\title{
An analysis of the Gender and Social Determinants of Health in Urban Poor Areas of the Most Populated Cities of Pakistan
}

\author{
Khawaja Aftab Ahmed ( $\sim$ kaahmed@unicef.org ) \\ UNICEF Pakistan \\ John Grundy \\ James Cook University \\ Lubna Hashmat \\ Civil Society Human and Institutional Development Programme - CHIP \\ Imran Ahmed \\ Civil Society Human and Institutional Development Programme - CHIP \\ Saadia Farrukh \\ UNICEF Pakistan \\ Dexter Bersonda \\ Muhammad Akram Shah \\ EPI Program, National Institute of Health (NIH) Pakistan \\ Soofia Yunus \\ EPI Program, National Institute of Health (NIH) Pakistan \\ Hari Krishna Banskota \\ UNICEF Pakistan
}

\section{Research Article}

Keywords: Gender, Immunization, Vaccination, Social Determinants, Pakistan

Posted Date: January 7th, 2022

DOI: https://doi.org/10.21203/rs.3.rs-1222208/v1

License: (c) (i) This work is licensed under a Creative Commons Attribution 4.0 International License. Read Full License

Version of Record: A version of this preprint was published at International Journal for Equity in Health on April 18th, 2022. See the published version at https://doi.org/10.1186/s12939-022-01657-w. 


\section{Abstract}

Background: Recent surveys, studies and reviews have highlighted the impacts of social inequities on access of women and children to health services for women and children in Pakistan. Utilising mixed methods for urban slum profiles, and facility and coverage surveys in 4431 urban poor areas of the top 10 highly populated cities of Pakistan, this paper describes and analyses the complex interactions between economic, social and gender determinants of health care access and considers health policy and program options for addressing them.

Results: Findings are classified into six analytic categories of (1) access to health services, (2) female workforce participation, (3) gender friendly health services, (4) access to schools and literacy, (5) social connections, and (6) autonomy of decision making. Out of a national sample of 14,531 children in urban poor areas of 10 cities, the studies found that just over half of the children are fully immunised (54\%) and $14 \%$ of children had received zero doses of vaccine. There are large shortages of health facilities and female health workforce in the slums, with significant gaps in the quality of health infrastructure, which all serve to limit both demand for, and supply of, health services for women and children. Results demonstrate low availability of schools, low levels of female literacy and autonomy over decision making, limited knowledge of the benefits of vaccination, and few social connections outside the home. All these factors interact and reinforce existing gender norms and low levels of health literacy and service access.

Conclusion: The Urban Slum profiles and coverage studies provide an opportunity to introduce gender transformative strategies that include expansion of a female health workforce, development of costed urban health action plans, and an enabling policy environment to support community organisation and more equitable health service delivery access.

\section{Background}

In recent years, as national health care systems across the globe step towards eradication and elimination targets for Vaccine Preventable Diseases (VPDs), increased policy and planning attention is being given to reaching the last 10-15 percent of unvaccinated or partially vaccinated populations, with an estimated 19.4 million of the world's children not receiving their basic vaccines in $2019 .{ }^{1}$ Multiple surveys across the globe show that this last segment of unreached population is often exposed to social or economic disadvantage, or are residing in urban poor 234 or remote geographic locations. ${ }^{5}$

The impact of gender on uptake of vaccination has been illustrated in several country studies. Analysis from three National Family Health Surveys in India between 1992 and 2006 found that girls were found to have significantly lower immunization coverage than boys. ${ }^{6} \mathrm{~A}$ recent study in rural Bangladesh in 2018 found that there is a significant variation in coverage according to the sex of the child in favour of the boys ( $89.2 \%$ versus $85.9 \%$ for girls).$^{7}$ In Pakistan, national surveys have demonstrated that there is a significant gap between the rate for fully immunised child of for males (68\%) than for females (63\%). ${ }^{8}$ In addition, lower status in the household and community, barriers relating to social position (including economic status, ethnicity, marital status, age, educational status, socio-cultural context), gender norms, levels of health literacy, and women's experience of quality of services have been identified as additional key gender-related barriers to immunization. ${ }^{9}$ Women, as primary care givers, require autonomy of decision making to ensure that both themselves and their children (both boys and girls) can readily access and utilise primary health care services. Autonomy of decision making also assumes a higher level of knowledge and participation by fathers in health and education. In several international and national settings, studies and reviews have demonstrated that such autonomy is compromised by socio cultural factors and gender norms. ${ }^{10} 11,12$ After controlling for socioeconomic variables, studies in Nigeria have found that household decision-making and domestic violence behaviours were significantly associated with a child being fully immunized. ${ }^{13}$ This is consistent with the findings of previous studies in Pakistan, that validate the lack of female autonomy over health care decision making, especially in rural areas and in urban slums, and how this limits their access to health care. ${ }^{14,15} \mathrm{~A}$ review of gender and health policy in Pakistan found that the fact that women had little decision making power about using health care services was due to women living within a set of societal norms, which preferences males for decision making, and places women in a subordinate position, all of which serve to increase vulnerability to illness. ${ }^{16}$

The reasons for these gender inequities involve complex interactions between health sector specific determinants as well as broader social influences on health seeking behaviours. ${ }^{17}$ These factors include education level, economic and political participation, and advocacy for reproductive health rights. ${ }^{18}$ This complexity in the gender related determinants of health is reflected in research findings in Pakistan on the economic, environmental, and social exposures related to low immunisation coverage. A cross sectional study of measles vaccination in one district in Pakistan found that having an educated mother, discussing vaccinations, having correct knowledge about vaccinations, living closer to health facilities and housing conditions were all factors associated with increased use of vaccination services. ${ }^{19} \mathrm{~A}$ review of the impact of early marriage found that it was associated with lower use of ante natal care and delivery assistance from skilled persons. ${ }^{20}$

Inequities in access to education means that health literacy can be gendered, in that limited understanding of immunisation reduces motivation to seek out vaccination services and negotiate the pathways of health system. ${ }^{9}$ These complex interactions are also reflected in health outcomes, with some studies demonstrating that doubling the proportion of girls educated at the secondary level reduces the fertility rate by 1.4 children per women and reductions in infant mortality rates by between five and ten percent for each additional year in a mothers schooling. ${ }^{18}$ This relationship between health and education is also inverse, with immunisation coverage contributing to improved growth and educational achievement in children. ${ }^{21}$ These interactions and feedback loops between gender, health and society are characteristics of complex adaptive systems, which challenges policy makers and planners to identify policy and planning points of engagement ${ }^{22}$ so as to reset the gender norms that currently set such rigid boundaries for the health seeking behaviours of households. 
Utilising the findings from urban slum profiles and immunization coverage surveys in slums and underserved areas in the 10 largest cities of Pakistan, this paper examines the extent to which gender is a determinant of health care service access and coverage for the urban poor in these ten cities. This will involve description and analysis of the complex interactions between economic, social and gender determinants of health care access revealed by survey findings and will conclude with a discussion of the potential health policy and planning options for addressing them.

\section{Methods}

The Urban Slum Profiles and coverage surveys were conducted between 2017 and 2019. The objective was to obtain an updated listing of slums and other underserved areas, and to better understand current vaccination and health service coverage in these areas, to set a baseline for development of urban health initiatives. The urban slums were identified in accordance with the international definition of slum areas, and underserved areas were identified by surveyors and provincial managers, based on criteria of low immunisation coverage and high rates of vaccine refusal. A total of 4431 areas were identified in the 10 cities,[1] of which 3031 were slums, with a total population of 19.6 million (comprising $48 \%$ of the total urban population of over 41 million ).

Urban Slum Profiles: There were four types of assessment that made up the urban slum profiles and included physical verification of slums and underserved areas, assessment of EPI Facilities $(n=422)$, mapping of coverage areas and assessing the level of health resources in the union councils (UCs). ${ }^{[2]}$ For sampling, after the list of slums and underserved areas was prepared, each UC was individually visited by the survey team to verify the slum areas. Following physically verification of the areas, information for a social profile was collected through group discussions with people belonging to those areas. The inclusion criteria included persons who has been living in the area for more than two years, and who had some knowledge of the physical infrastructure and other facilities of that area. Residents who resided in the areas for less than two years were excluded. The EPI facility surveys were conducted using a structured questionnaire. This included physically assessing for the facilities for health and vaccination services and basic facilities for patients. All EPI facilities listed by the Department of Health in slums and underserved areas were assessed without any sampling. In addition to physical verification, social profiling and facility surveys, consultations were undertaken at the District level in each city for providing official information on health resources in the survey areas.

Coverage Survey: The immunization coverage survey in slums and underserved areas of 14491 mothers and 14531 children in 10 cities was conducted according to the protocols of the World Health Organisation on immunisation coverage surveys. ${ }^{23}$ These surveys also collected data on knowledge of vaccination and health care services, which was triangulated with the urban slum profile assessments and focus groups discussions conducted in the field on the topics of immunisation and health services access. Survey questionnaires covered topics including physical features of the houses, economic situation of the households, profile of mothers, and the status of vaccination. The details for the study design, including survey sites, sampling methodology and procedure including variables, analysis, team composition and monitoring system, are detailed in the National Urban Slum Profile 24 and Coverage Survey Reports. ${ }^{25}$

These profiles and coverage surveys were conducted as part of internal program evaluation and were conducted under the stewardship of the Provincial Expanded Program of Immunisation (EPI), local government and civil and international agencies. Gender, although not the primary survey objective, was mainstreamed into survey design, particularly in relation to establishing associations between health coverage and the background characteristics of households.

As an internal method of evaluation designed to improve program and health system performance, this research combines both quantitative and qualitative research. It can be best categorised as a model of "implementation research," whose principal concern is how interventions work in real world settings. ${ }^{26}$ One of the main limitations of this research relates to the need to "embed" research within implementing institutions, ${ }^{27}$ to increase the probability for take up of recommendations into policy and practice. This raises the risk that data collection can be subject to systematic bias. Researchers and implementers tried to mitigate this risk through triangulation of findings from multiple data sources including from quantitative survey methods, focus group discussion with community members, and physical verification of slum areas and facilities.

\section{Approach To Analysis}

The approach to analysis was guided by searching through the urban slum profile reports and through examination of coverage survey data bases and profile reports for gender related data, analysis, commentary, or recommendations. The design of the survey tools facilitated this approach as the urban slum profiles were constructed to provide a social determinants of health perspective, through examination of information on demography, infrastructure, social services, health services and assessments of health resources in the slums.

Figure 2 was constructed following extraction of information on gender from the urban slum profile reports and survey data and classifies gender related information in these profiles according to the seven categories.

This framework provides a means by which to classify and describe the information (refer to findings section), as well as a means by which to examine interactions and feedback loops between the different categories, which all reflect the lived experiences and social conditions of women and their families in the slums. 
Some elements of gender theory including how gender norms are socialised through inequitable power relations between men and women, or how rules of governing institutions and social interaction both reflect and reinforce gender norms. Both of these perspectives will be applied in relation to discussion of main policy and planning implications of findings in the concluding section. ${ }^{28}$

\section{Results}

\subsection{Availability of Health Services}

These inequities in reproductive health care access relate not only to gaps in provision of types of services, but also to availability of facilities. Overall, of the UCs where health resource assessments were conducted $(n=636), 26 \%(n=165)$ are without EPI Facilities, and 31\% ( $n=197)$ are without any health facilities at all (whether public or private).

Fixed facilities are a requirement for most reproductive health services. Only $3 \%(n=232)$ of the slums and underserved areas out of a total of 4431 areas in ten cities are located within a 3 kilometre distance from the slum areas, and $29 \%(n=1285)$ of the slum and underserved areas do not receive health outreach services from fixed facilities. Limited transport also impedes accessibility. In Quetta City of Balochistan Province, the Urban Slum Profile reports that access by female caregivers to health facilities is limited by the fact that there are scattered residential areas which are devoid of gender friendly transport facilities. ${ }^{29}$ In Karachi, with a population of 7,645,375, only $9 \%$ of the public health facilities located in the slums have an ambulance service. Although trends in facility delivery are improving (66\% in 2017-2018 compared to 13\% in 1990-91), it remains the case that 1 in 3 births are still occurring at home. ${ }^{30}$

\subsection{Female Workforce Participation}

In the context of gender and health, workforce participation can refer to participation by women in the general workforce generally or in the health workforce specifically. In collecting data on the household characteristics in the national coverage survey, information was sought on the current employment status of women and men in the households, with 14491 women mothers being interviewed in the slums and underserved areas of 10 cities.

Nationally, of the 14491 women surveyed in 4431 slum and underserved areas in 10 cities, only $6 \%$ ( $n=833$ ) had employment outside the home. Workforce participation rates for mothers were as low as $3 \%$ in Rawalpindi ( $n=26$ of 824 respondents) and $2 \%$ in Faisalabad ( $n=13$ out of 712 respondents).

This low workforce participation rate may be partly because the mothers interviewed all had children between ages 12 months and 23 months (the age parameters for inclusion in the immunisation coverage survey). However, these findings are consistent with other findings on female workforce participation, which illustrate that, despite some growth in recent decades, female labour force participation in Pakistan is well below that of other countries with similar national incomes. An analysis of Province wide female workforce participation to population ratios in $2017-2018$ found such rates were low in Balochistan (6.7\%) and KPK (9.3\%) provinces, compared to rates in Sindh of 9.3\% and in Punjab Province of $22.7 \%$. ${ }^{31}$

These low rates are attributable in part to the persistence of gender norms, which identify males of the households as the major income earners and decision makers, resulting in the confining of women at home, or restricting female workforce participation to certain socially acceptable labour force roles. The persistence of these gender norms reduces workforce participation, which in turn reduces productivity and constrains household incomes. ${ }^{32}$

The association between low female workforce participation and socio-economic status are further reinforced by the findings of the immunization coverage survey in slums and underserved areas. Of the 14,467 households surveyed, $54 \%(n=7846)$ of households derive incomes from daily wages and $56 \%$ of households $(n=8060)$ are either occasionally or are always in income deficit. Just $6 \%$ of households $(n=888)$ experience income surplus (i.e. have household savings).

One opportunity presented in the Urban Slum Profiles for improvement in health and social conditions is increased participation of Lady Health Workers (LHWs) and Visitors (LHVs) in PHC programs. This is not only a method of increasing female workforce participation but is also a means of providing more "gender friendly" health care services for maternal and child health care. The National Urban Slum Profile indicates that lack of female health sector workforce participation is a "discouraging factor" for attendance of women and children at health facilities. ${ }^{23}$

The primary function of the Lady Health Visitor (LHV) is to provide maternal and child health care. The survey of EPI facilities in eight cities found that $39 \%(n=163)$ of EPI facilities do not have LHVs placed in them. Of the 636 Union Councils in eight cities, the urban slum profiles confirmed that $25 \%$ $(n=157)$ were not covered by LHWs. The regular visits of LHWs in the slum communities are important because these health workers educate and promote healthy behaviour and provide basic curative healthcare services, but overall, across the eight cities in which the urban profiles were conducted, it was found that $58 \%$ of the slums and underserved areas are not covered

by LHWs. ${ }^{24}$ This lack of availability is confirmed by interviews with 14,491 mothers during the immunisation coverage survey in 10 cities, which found that only $56 \%(n=8166)$ know about the work of LHWs.

\subsection{Gender Friendly Health Services}


The term "gender friendly health services" is applied in the profiles in the context of facility design, including waiting room arrangements and water and sanitation infrastructure, and the degree to which these categories of infrastructure are gender disaggregated.

Overall, $58 \%(n=238)$ out of the 422 facilities surveyed in eight cities did not have gender segregated waiting areas. Additionally, $43 \%$ ( $n=180)$ of the 422 facilities did not have gender segregated toilet areas for patients and staff, and $26 \%(n=11)$ of facilities had no toilet facilities at all. Water supplies were available at only $65 \%(n=276)$ of the 422 surveyed facilities. Gender segregated waiting areas were available at $42 \%(n=172)$ of the 422 surveyed facilities. Seven out of eight cities report inadequate seating capacity at clinics in or near slums and underserved areas. The National Urban Slum Profile indicated that the fact that $31 \%$ percent of the toilet facilities were gender mixed presented a "cultural barrier for females for easy use", especially in cities such as Peshawar and Quetta where female caregivers may be considerably discouraged to get their children vaccinated due to the lack of such facilities. ${ }^{22}$ Issues of privacy of examination rooms inside clinics were not examined in the profiles.

Availability of reproductive health services, female workforce participation and gender friendly health infrastructure could all legitimately be classified as constituting "gender friendly health services." Presentation of findings will now extend beyond the health sector to include description and analysis of gender issues reflected in educational attainment, social connections and welfare service, as well as autonomy of decision making.

\subsection{Schools and Health Literacy}

The urban slum profiles confirm that there are strong connections between a mother's educational status and the coverage of vaccination in their children. These findings are attributable to several factors, including knowledge of mothers about the benefits of vaccination. In the national sample of 14,491 mothers of children aged $12-23$ months, just $67 \%(n=9659)$ could state that vaccination protects from diseases, with the remaining $33 \%$ ( $n=4832$ )either not knowing or stating other reasons for vaccination being given.

A second reason is lack of access to school education. Overall, $27 \%$ of slums and underserved areas are without schools. Of the 1,978 mothers in the national coverage survey who had children with zero doses of vaccines, 1,505 (76\%) had zero years of schooling, in contrast with the mothers of children of fully immunised children, of whom $47 \%(n=3598)$ had zero years of schooling. The links between schooling and development is summed up in this extract from the qualitative discussions:

"I still remember the day when I was married to him (my husband). I was 14 years old and in the 8th grade. I had ambitions of pursuing higher education and making something out of myself so that I could have a better life than my parents had and could choose a better life for my children-to-be. It seems it was not in the cards, after all."33

There are two further criteria which can be applied relating to access to information about vaccination and modern health care. These include social connections and autonomy of decision making, both of which will be taken up in the following sections.

\subsection{Social Connections}

The Urban Slum profiles report widely on the availability of community based and civil organisations in communities in eight of the ten cities, as well as on the number of formal and informal groups available in the slums and underserved communities, as outlined in Table 1.

Table 1

Prevalence of Community Organisations and Social Welfare Schemes in Slums and Underserved Areas in 8 Cities $(n=3114)$

\begin{tabular}{|c|c|c|c|}
\hline \multicolumn{2}{|c|}{ Types of Groups and Schemes in 3114 Urban Slum or Underserved Areas in Eight Cities } & \multirow{2}{*}{$\begin{array}{l}\text { No. } \\
1082\end{array}$} & \multirow{2}{*}{$\begin{array}{l}\% \\
35 \%\end{array}$} \\
\hline $\begin{array}{l}\text { Informal } \\
\text { Groups }\end{array}$ & $\begin{array}{l}\text { Masjid/Church, Zakat, School or Health Committees, Unregistered Community Based Organisations, } \\
\text { Jirga/Punchaiyat }\end{array}$ & & \\
\hline Civil Society & Education, Health, Loans, Water, Human Rights & 72 & $2.3 \%$ \\
\hline Social Welfare & Loan and Stipend Schemes, Social Benefit Cards, Vocational Skill program. & 1512 & $49 \%$ \\
\hline
\end{tabular}

The information demonstrates extremely low levels of formation of community level organisation and social connections with regards to health and education. These observations, coupled with the fact that only $6 \%$ of women surveyed work outside the home, suggest that lack of knowledge and demand and supply of services is not being compensated for through community organisation and social networks. It reinforces earlier findings of limited knowledge of households of the benefits of vaccination. It also raises questions about access of women to sufficient channels of communication enabling them to make autonomous and informed decisions about use of modern health and education services.

\subsection{Autonomy of Decision Making}

The immunization coverage survey in slums and underserved areas found that, of 14,441 mothers, 1985 of their children (14\%) did not receive any vaccine. As illustrated in in figure 3, the most common response for why children did not receive vaccines was that family permission was not given (33\%, 
$\mathrm{n}=647$ )., with particularly high response rates for non-permission in the slums of Karachi (48\%), and Quetta and Peshawar (both $43 \%$ ). As figure 3 illustrates, there are also other reasons include 'fear of side effects', 'no time for vaccination' and unaware of vaccination timings etc.

This lack of autonomy over decision making and limited social connections and availability of schools, coupled with low availability of a female health workforce participation, all interact to create a powerful social and institutional web of influence excluding women from informed decision making about health care. The following extracts from the Karachi urban slum profile highlight the challenges and complex dynamics of the urban poor women in seeking out health care:

"It is very difficult to find time to go out of home. My husband takes care of responsibilities outside home...my husband does not allow me to travel alone and he does not have time available to take kids for vaccination by himself as it results in forgoing a day's wage." "28

'Bareera aged 12 months and 2 days, lives in a small, dilapidated slum ... Residing here for the past 07 years, their house is composed of 02 rooms in which a total of 11 people live. ......... Aged 24, Bareera's mother is illiterate and has not ever received any formal education. She is completely unaware of childhood vaccination and its significance. She says: "Bareera has not received any vaccination due to her grandfather's disapproval. He becomes infuriated by such a proposition and is highly sceptical of the presence of men in vaccination centers...." 34

From a perspective of inequities, autonomy of decision making not only relates to the issue of equal access of girls and women to vaccination services. It also remains the case that, even though there are significantly more boys fully immunised than girls, that fact that a significant minority of boys are still not fully vaccinated demonstrates that a mother's lack of autonomy in decision making affects access of both boys and girls to primary health care services. A plausible explanation for a significant proportions of boys not being fully vaccinated is related to the fear of side effects as illustrated in figure 3.

\subsection{Inequities in Health and Social Outcomes}

Given the reported low availability of a female health workforce, health facilities and reproductive health services in the slums as reported in sections 4.14.3 of this paper, it would be reasonable to conclude that reproductive health and child mortality outcomes are likely to be comparable to PDHS findings in 2018. Although there are narrow gender gaps between fully immunised boys (54\%) and fully immunised girls (53\%) in the immunization coverage survey in slums and underserved areas, from a gender and public health impact perspective, the critical intervention for consideration is the role of women as primary health care givers supporting improved access of both girls and boys to immunization and other health services. Vaccination coverage rates are significantly lower in urban poor settings, with the Pakistan Demographic and Health Survey (PDHS) in 2018 demonstrating a coverage rate of $66 \%$ for fully immunised child rate compared to $54 \%$ (fully immunised child) in the urban health coverage survey. ${ }^{35}$

\section{Discussion}

\section{Summary of Main Findings}

Equity remains central to Global Immunization Agenda 2030 and evidence shows that most of the zero dose children are found in communities where gender disparities are highly prevalent. Policy reviews, ${ }^{13}$ previous studies ${ }^{11}$ and commentary ${ }^{17}$ in Pakistan demonstrate that more research is needed to understand the complex interactions between various social forces that contribute to gender inequities in health care access and its eventual outcomes. As the findings from the urban slum profiles have demonstrated, complexity is illustrated in the multiple determinants of such inequities, that have included availability of health services, access to schooling, levels of health literacy, workforce participation and social connections, and autonomy of female decision making, all against a backdrop of socio-economic deprivation and the guiding narratives of gender norms.

These gender norms are characterised by inequitable power relations that disadvantage women in such areas as access to schooling, availability of reproductive health services and autonomy in decision making. Lack of social connections means that there are limited opportunities for gaining access to the required health information to make informed decisions, as well as limiting the development of the capabilities and social organisation to question gender based social disadvantage. Institutional policies and regulations that limit placements of schools, health facilities, social welfare support and a female health workforce in slums and underserved areas reinforces social disadvantage that is already being socialised in the urban poor communities.

Constraints on female workforce participation not only constrain social connections and household incomes but have adverse effects on socio-economic development more generally. A clear linear relationship has been established in many countries between increased rates of female workforce participation and increased Gross Domestic Product (GDP), ${ }^{3637}$ suggesting that there are significant opportunities in Pakistan to accelerate socio economic development through reducing gender inequities. Current cultural standpoints, social conditions, and institutional and policy settings means that current gender norms are being both socialised and institutionalised. ${ }^{26}$ This demonstrates the 'intersectionality' of gender related health inequities, whereby it is the interaction between the broader social determinants of health and gender norms which are locking families into multi-generational cycles of health and social disadvantage. ${ }^{38}$

\section{Health and Social Policy and Planning Implications}

Page 6/11 
Given this level of intersectionality when considering gender and health, and in the light of the findings in this paper of overlapping and interacting gender and social disadvantage, what health policy and planning initiatives can be feasibly applied to negotiate a pathway through this complex maze of gender, health system and social determinants of health?

The Urban Slum profiles provide several recommendations in this regard, especially in relation to investment in a community-based female health workforce strategy. Although women constitute $56 \%$ of front-line workers in Pakistan, ${ }^{39}$ the main issue in the slums is the lack of absolute numbers of female health providers with capabilities to provide the full range of PHC services. Expanding the network of Lady Health Workers (LHWs) and Lady Health Volunteers (LHVs) based in PHC facilities will bring services and health knowledge closer to communities in a gender friendly manner, through expanded access to health knowledge, health outreach services and a female health workforce placed in EPI or renamed PHC facilities that are in or near the slums. This will require reforms to institutional policies, since, under current health administrative policies and arrangements, EPI facilities are mainly staffed by "vaccinators" 22 and are hence restricted in their capability to provide reproductive health care services.

Another potential point of entry into the complex web of the social and gender determinants of health in the slums is investment in civil society and community based organisations, and informal groups, to provide viable and reliable communications to mothers, fathers and community leaders on the benefits of vaccination and reproductive health care services. This may also require reforms to institutional arrangements and policies of provincial and local governments to ensure that there is a favourable climate for building of such health partnerships and collaborations.

There are also longer term institutional policies that will be required to support these directions which are clearly identified in the slum profiles, including development of urban health strategy and costed coverage plans, rebuilding of health infrastructure, improvements to housing and environmental conditions, advocacy for improved educational opportunities for girls and boys, and legal recognition of slums. Given the scale and longer term nature of such developments, building of a female workforce and community based social organisation to support health communications will in all probability be necessary conditions for ensuring there is adequate and capable social pressure to advocate for such longer term social, institutional and policy change. Such reforms have the potential to be the precursor to a shifting of a "people's narrative" ${ }^{26}$ on gender norms, especially with regards to the role of women in health care and in employment outside the home more generally.

The idea of shifting of the of peoples' and institutions' narrative on social and gender norms demonstrates that, although feasible points of engagement are required to make earlier gains in reduction of gender related health inequities, in the longer term an "ecological" strategic approach is required, that takes into account the multiple and overlapping determinants of health inequities that have been outlined in these urban studies. ${ }^{40} \mathrm{An}$ illustration of the importance of an ecological approach is demonstrated by the observation that the retention of women in the health workforce is influenced by the broader set of social and gender norms, with female health workers being required to "operate within the same gender systems that necessitate their appointment in the first place." 41 It is for this very reason that that there needs to be a clear understanding of both social and health system dynamics to expand services for the most vulnerable or marginalised communities. These observations on what needs to be done are consistent with the recommendations of a global review on gender and immunisation. ${ }^{9}$ The recommendations in this review (see below) highlight the importance of raising awareness of the role of social norms and household dynamics in transforming the way we think about gender and inequalities.

\section{Conclusion}

The Urban Slum Profiles and immunization coverage survey in slums and underserved areas have found that the determinants of health and gender inequities are interacting and are having wide ranging impacts on health care access for the urban poor. This being the case, the calculation and design of an initial short to medium term strategy will be critical to lay the ground for a longer-term ecological approach. The findings from these studies provide an opportunity to develop a more gender and pro-equity focussed urban health strategy and costed action plans aligned with the national and provincial health plans, through the expansion of a female health workforce, in combination with institutional policies to support improved service availability and community organisation for health. Given the fact that over 13 million people are living in these urban poor areas in the 10 cities, the mainstreaming of gender into urban health strategy and operations has the potential to empower women towards more of a gender equal society, as well as improve access to essential health and social services. In doing so, such mainstreaming of gender policy demonstrates the potential to make a substantial contribution to the overall economic and social development of Pakistan.

\section{Declarations}

\section{- Ethics approval and consent to participate}

Approval was not sought from an institutional ethics committee, as the studies were part of formal program evaluation.

\section{- Consent for publication}

Not Applicable

\section{- Availability of data and materials}

Refer to references [24], and [25] 


\section{- Competing interests}

The authors have no competing interests

\section{- Funding}

This program of research was co funded through National Immunization Support Project (NISP)/Multi donor trust funds (MDTF), Gavi, the Vaccine Alliance and the EPI Program Pakistan

\section{- Authors' contributions}

KA was the technical lead for the urban slums profiling and study and provided overall coordination, concept development, capacity building, training and monitoring of the third party involved in implementation. JG supported analysis of findings and drafted the original paper. LH undertook data Collection/ implementation of the study. IA supported data collection and monitoring in the field. SF supported review of the paper and DB undertook data analysis. AS, SY, YC and HB supported oversight and coordination with provincial and districts counterparts Supported funding arrangement.

\section{- Acknowledgements}

We hereby acknowledge the substantial efforts undertaken by the following Organisations in facilitating implementation of the urban health studies. These include the management and staff of the Federal and Provincial EPI Programs as well as the District Health Offices in the ten mega cities and for the technical advice provided by the staff of the World Health Organization and Civil Society Human and Institutional Development Program (CHIP). We would also extend our acknowledgements to UNICEF country office (Immunization team) and sub offices for their technical support, coordination and monitoring during implementation of this research, as well as to Regional and Headquarter technical staff especially Alyssa Sharkey, for their supervision and review of this paper. We also extend our thanks to Gavi- the vaccine Alliance for the commitments to improvements in vaccination services in Pakistan. Most of all, we would like to extend our appreciation to the many field researchers, health workers, managers and community members who participated in our field research.

\section{References}

1. World Health Organisation Fact Sheet Immunization Coverage 2018 WHO Geneva https://www.who.int/news-room/fact-sheets/detail/immunizationcoverage [accessed June 27th 2020]

2. Kristin N. Nelson, Aaron S. Wallace,Samir V. Sodha, et al; Assessing strategies for increasing urban routine immunization coverage of childhood vaccines in low and middle-income countries: A systematic review of peer-reviewed literature Vaccine. 2016 Nov 4; 34(46): 5495-5503.

3. Crocker-Buque T, Mindra G, Duncan R, Mounier-Jack S. Immunization, urbanization and slums - a systematic review of factors and interventions. BMC Public Health. 2017;17(1):556. Published 2017 Jun 8. doi:10.1186/s12889-017-4473-7

4. Boyce T, Gudorf A, de Kat C, Muscat M, Butler R, Habersaat KB. Towards equity in immunisation. Euro Surveill. 2019;24(2):1800204. doi:10.2807/1560-7917.ES.2019.24.2.1800204

5. The DHS program Demographic and Health Surveys https://dhsprogram.com/ [accessed June 25th 2020]

6. Daniel J Corsi 1 , Diego G Bassani, Rajesh Kumar, Shally Awasthi, Raju Jotkar, Navkiran Kaur, Prabhat Jha Gender Inequity and Age-Appropriate Immunization Coverage in India From 1992 to 2006BMC Int Health Hum Rights 2009 Oct 14;9 Suppl 1(Suppl 1):S3. doi: 10.1186/1472-698X-9-S1S3.a

7. Rahman A, Reza AAS, Bhuiyan BA, et al. Equity and determinants of routine child immunisation programme among tribal and non-tribal populations in rural Tangail subdistrict, Bangladesh: a cohort study. BMJ Open. 2018;8(10):e022634. Published 2018 Oct 24. doi:10.1136/bmjopen-2018-022634

8. National Institute of Population Studies (NIPS) [Pakistan] and ICF. 2019. Pakistan Demographic and Health Survey 2017-18. Islamabad, Pakistan, and Rockville, Maryland, USA: NIPS and ICF.

9. Feletto M, A Sharkey, Rowley E et al A Gender Lens to advance Equity in Immunisation December 2018 Equity Reference Group for Immunisation 2018 https://www.researchgate.net/publication/331593391_A_gender_lens_to_advance_equity_in_immunization\{accessed Sept 10 2020]

10. Kavita Singh, Erica Haney, Comfort OlorunsaiyeMaternal Autonomy and Attitudes Towards Gender Norms: Associations With Childhood Immunization in NigeriaMatern Child Health J . 2013 Jul;17(5):837-41. doi: 10.1007/s10995-012-1060-5.e

11. Babar T, Hatcher J: Health seeking behaviour and health service utilization in Pakistan: Challenging the policy makers. Journal of Public Health 2005, 27:49-54.

12. Hamid S, Johansson E, Rubenson B. Security lies in obedience voices of young women of a slum in Pakistan. BMC Public Health $2010 ; 10: 164$.

13. Kavita Singh, Erica Haney, Comfort OlorunsaiyeMaternal Autonomy and Attitudes Towards Gender Norms: Associations With Childhood Immunization in NigeriaMatern Child Health J . 2013 Jul;17(5):837-41. doi: 10.1007/s10995-012-1060-5.e

14. Babar T, Hatcher J: Health seeking behaviour and health service utilization in Pakistan: Challenging the policy makers. Journal of Public Health 2005, 27:49-54.

15. Hamid S, Johansson E, Rubenson B. Security lies in obedience voices of young women of a slum in Pakistan. BMC Public Health 2010; $10: 164$. 
16. Narjis Rizvia, Sania Nishtarb Pakistan's health policy: Appropriatenessand relevance to women'shealth needsHealth Policy2008; 88 269-281

17. Rainey JJ, Watkins M, Ryman TK, Sandhu P, Bo A, Banerjee K. Reasons related to non-vaccination and under-vaccination of children in low- and middle-income countries: findings from a systematic review of the published literature, 1999-2009. Vaccine. 2011 Oct 26;29(46):8215-21. doi: 10.1016/j.vaccine.2011.08.096. Epub 2011 Sep 3. PMID: 21893149.

18. Narjis Rizvia, Sania Nishtarb Pakistan's health policy: Appropriatenessand relevance to women'shealth needsHealth Policy 88 (2008) $269-281$

19. Mitchell S, Andersson N, Ansari NM, Omer K, Soberanis JL, Cockcroft A.Equity and vaccine uptake: a cross-sectional study of measles vaccination in Lasbela District, Pakistan. BMC Int Health Hum Rights. 2009 Oct 14;9 Suppl 1:S7. doi: 10.1186/1472-698X-9-S1-S7.

20. Nasrullah M, Zakar R, Krämer A Effect of child marriage on use of maternal health care services in Pakistan.Journal of the College of Physicians and Surgeons Pakistan 2012, Vol. 22 (5): 273-274 Obstet Gynecol. 2013 Sep;122(3):517-24. doi: 10.1097/A0G.0b013e31829b5294. .

21. Bloom DE. The value of vaccination. Adv Exp Med Biol. 2011; 697:1-8. doi:10.1007/978-1-4419-7185-2_1

22. Hill P, 2011 Understanding global health governance as a complex adaptive system Glob Public Health 2011;6(6):593-605Epub 2011 May 24.

23. World Health Organization Vaccination Coverage Cluster Surveys: Reference Manual WHO Geneva 2018

24. UNICEF/CHIP Report of Profiles of Slums/Underserved Areas of the 8 Largest Cities of Pakistan UNICEF Country Office Islamabad January 2020 https://www.unicef.org/pakistan/media/2926/file/Profiles\%20of\%20Underserved\%20Areas\%20of\%2008\%20Largest\%20Cities\%20of\%20Pakistan.pdf [Accessed Dec 31 2021]

25. UNICEF Report of Coverage Survey in Slums/Underserved Areas of 10 Largest Cities of Pakistan January 2020 Punjab UNICEF Country Office Islamabad January 2020 https://www.unicef.org/pakistan/reports/coverage-survey-slumsunderserved-areas-10-largest-cities-pakistan [Accessed Dec 31 2021]

26. Peters D, Tagrheed A et al Implementation research: what it is and how to do it? BMJ 2013;347:f6753doi:10.1136/bmj.f6753(Published 20November2013

27. Sally Theobald, Neal Brandes, Implementation research: new imperatives and opportunities in global health Lancet 2018; 392: 2214-28 Published Online October 9, 2018 http://dx.doi.org/10.1016/ S0140-6736(18)32205-0

28. Beniamino Cislaghi and Lori Heise Gender norms and social norms: differences, similarities and why they matter in prevention science Sociol Health IIln. 2020 Feb; 42(2): 407-422. Published online 2019 Dec 13e

29. UNICEF, CHIP Situation Analysis of Slums and Underserved Areas of Quetta City of Balochistan Province of Pakistan Unpublished Report UNICEF Country Office Islamabad Nov 25, 2019

30. National Institute of Population Studies Islamabad, Pakistan Pakistan Demographic and Health Survey (PDHS) 2017-2018. January 2019. https://dhsprogram.com/pubs/pdf/SR257/SR257.pdf [Accessed September 29th 2021]

31. Government of Pakistan Ministry of Statistics Pakistan Bureau of Statistics Employment Trends 2018 http://www.pbs.gov.pk/sites/default/files/Pakistan\%20Employment\%20Trend\%20\%20Reprt\%202018\%20Final.pdf [Accessed September 14th 2020]

32. Asia Development Bank Policy Brief on Female Labour Force Participation in Pakistan 2016 https://www.adb.org/sites/default/files/publication/209661/female-labor-force-participation-pakistan.pdf [accessed June 17th 2020]

33. UNICEF, CHIPs Profiling of Slums and Underserved Areas of Faisalabad, Gujranwala, Lahore, Multan, Rawalpindi Punjab Province of Pakistan November 25, 2019 Unpublished UNICEF Country Office Islamabad

34. UNICEF, CHIP Childhood Immunization Coverage Survey in Slums of Karachi \& Hyderabad, Sindh Province of Pakistan November 19, 2019 Unpublished Report Country Office Islamabad

35. The DHS program Demographic and Health Surveys https://dhsprogram.com/ [accessed June 25th 2020]

36. International Labour Organization. 2014. Global Employment Trends. Geneva.

37. World Bank. 2014. World Development Indicators. Washington, DC.

38. Hankivsky O, Women's health, men's health, and gender and health: Implications of intersectionality Social Science \& Medicine Volume 74, Issue 11, June 2012, Pages 1712-1720

39. Global Polio Eradication Initiative technical brief: gender. Geneva: World Health Organization; 2018 (WHO/ Polio/18.05). Licence: CC BY-NC-SA 3.0 IGO. Polio Global Eradication Initiative

40. Feletto $M$ \& Sharkey $A B$. The influence of gender on immunisation: using an ecological framework to examine intersecting inequities and pathways to change. BMJ Global Health 2019;4:e001711. doi:10.1136/bmjgh-2019-001711.

41. Mumtaz Z, Salway S, Waseem M, Umer N. Gender-based barriers to primary health care provision in Pakistan: the experience of female providers. Health Policy Plan. 2003;18(3):261-269. doi:10.1093/heapol/czg032

\section{Figures}




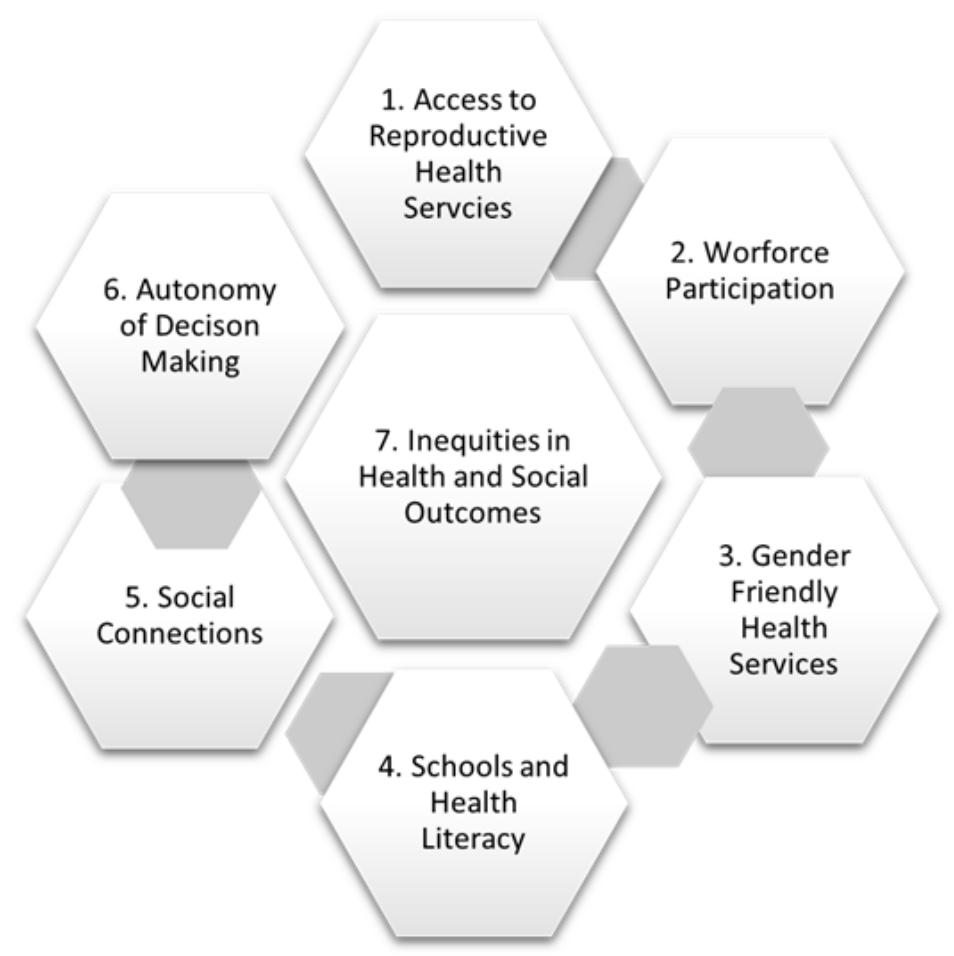

Figure 1

Classification of Gender Related Information Urban Slum Profiles Pakistan 2017-2019

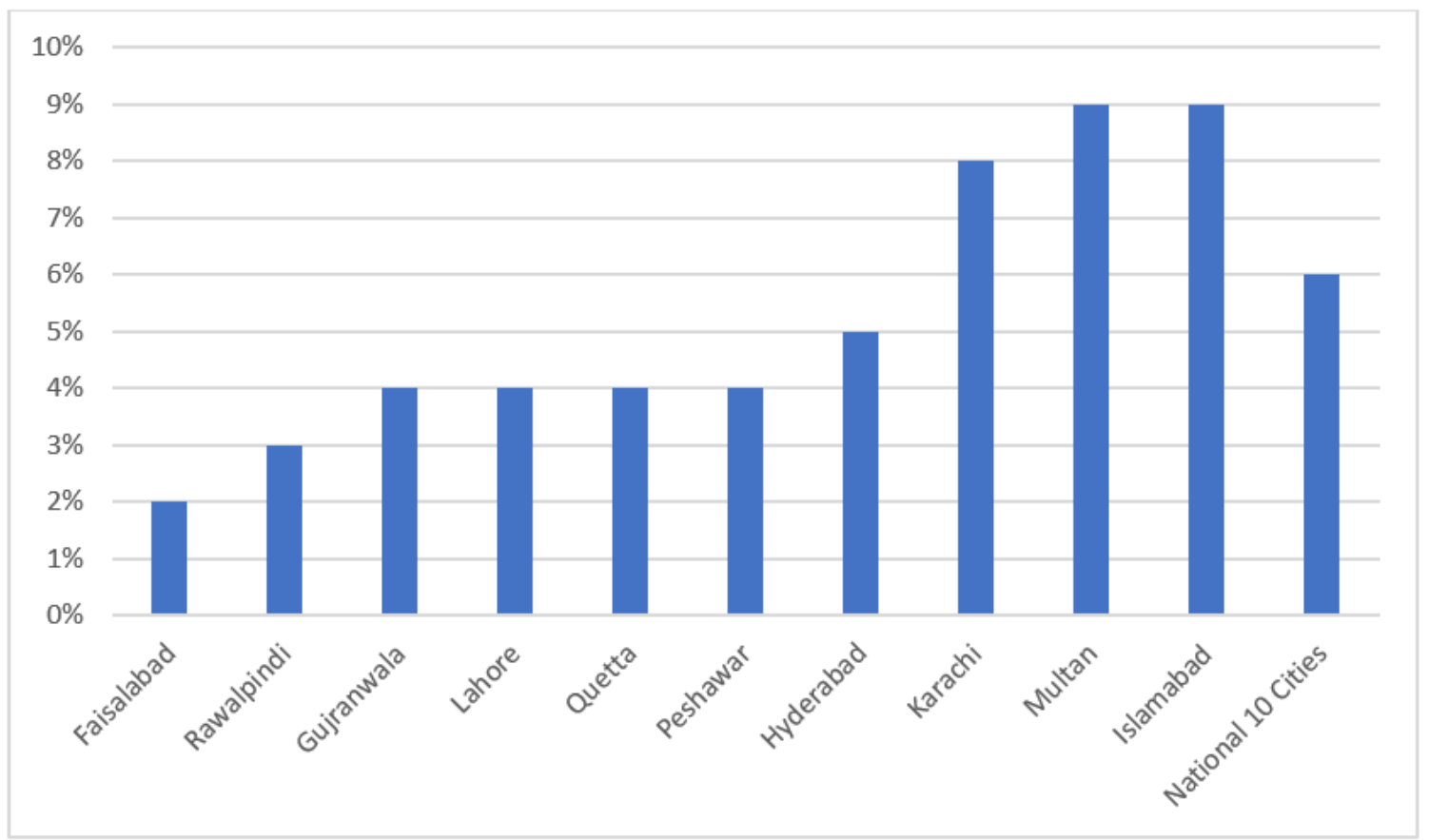

Figure 2

Percentage of Mothers with Employment Outside the Home in Urban Slums and Underserved Areas in 10 Cities 


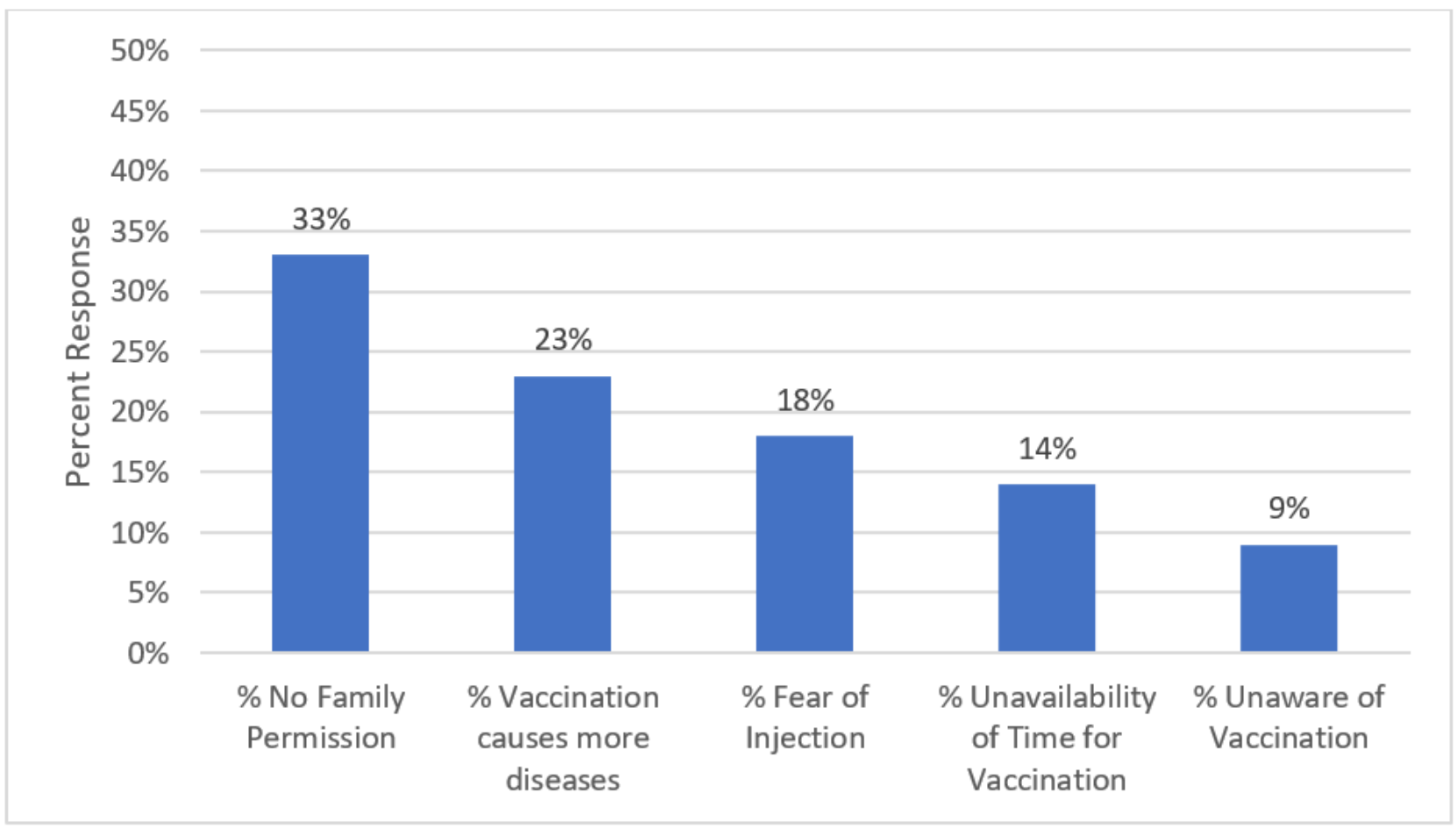

Figure 3

Mothers Reasons for Zero Dose of Children ( $n=1985)$

- Assess context-specific household-decision making dynamics, and key influencers within communities to plan, implement and monitor immunization services for the most vulnerable

- Leverage existing funding options to provide support for pro-gender demand \& supply-side strategies, including strategies that support integration of immunisation with other reproductive and child health services

- Explore Opportunities for gender transformative approaches aiming to achieve long-term change in the underlying social norms that drive gender inequality

Figure 4

Selected Recommendations from a Global Review of Gender and Immunisation 